\title{
Parenting in mothers with borderline personality disorder and impact on child outcomes
}

\author{
Lara Petfield, ${ }^{1}$ Helen Startup, ${ }^{2}$ Hannah Droscher, ${ }^{1}$ Sam Cartwright-Hatton ${ }^{1}$
}

${ }^{1}$ School of Psychology, University of Sussex, Brighton, UK; ${ }^{2}$ Sussex Partnership NHS Foundation Trust, Sussex Education Centre, Hove, UK

Correspondence to Dr Helen Startup; helen.startup@kcl.ac.uk

\begin{abstract}
Question This systematic review explores two questions: what parenting difficulties are experienced by mothers with borderline personality disorder (BPD); and what impact do these have on her children?

Study selection and analysis Studies had to include mothers with a diagnosis of BPD, who was the primary caregiver to a child/children under 19 years. PsycINFO and MEDLINE were screened (update: July 2014), yielding 17 relevant studies.

Findings Mothers with BPD are often parenting in the context of significant additional risk factors, such as depression, substance use and low support. Interactions between mothers with BPD and their infants are at risk of low sensitivity and high intrusiveness, and mothers have difficulty in correctly identifying their emotional state. Levels of parenting stress are high, and self-reported competence and satisfaction are low. The family environment is often hostile and low in cohesion, and mothers with BPD show low levels of mind-mindedness but high levels of overprotection of older children. Outcomes for children are poor compared with both children of healthy mothers, and mothers with other disorders. Infants of mothers with BPD have poorer interactions with their mother (eg, less positive affect and vocalising, more dazed looks and looks away). Older children exhibit a range of cognitive-behavioural risk factors (eg, harm avoidance, dysfunctional attitudes and attributions), and have poorer relationships with their mothers. Unsurprisingly, given these findings, children of mothers with BPD have poorer mental health in a range of domains.

Conclusions This review highlights the elevated need for support in these mother-child dyads.
\end{abstract}

\section{BACKGROUND}

Borderline personality disorder (BPD) affects around $0.7-1 \%$ of the British population. ${ }^{1}$ Although there is much controversy over its definition and diagnosis, it is generally agreed to be characterised by difficulties in emotion regulation, and interpersonal relationships. Some individuals with BPD struggle with empathy, resulting in difficulties identifying and understanding others' feelings. Relationships are often unstable and of high intensity, characterised by insecurity, hostility and lack of trust. They often exhibit chronic concerns about rejection and abandonment, most pronounced in close interpersonal relationships. Anxiety and depression are common in BPD, as are impulsivity and risk-taking. ${ }^{2}$

Individuals with BPD can also experience disturbances in their sense of identity, exhibiting unstable self-image, excessive self-criticism, and feelings of emptiness. ${ }^{2}$ Their self-presentation can fluctuate depending on the group or situation they are in, with the sufferer's sense of identity being experienced as dependent on a specific relationship. ${ }^{3}$

It is now widely accepted that mental health difficulties in parents impact on parenting and, subsequently, on outcomes for the child. ${ }^{4-7}$ However, despite the clear need for it, there is a paucity of research into the influences of parental BPD on parent as well as child. To the best of our knowledge, no attempt has been made at synthesis of the little that does exist. A better understanding of the impact of BPD on parenting and on children's outcomes might inform the development of interventions for this vulnerable group.

\section{OBJECTIVES}

Considering that BPD is most commonly diagnosed in women, ${ }^{8}$ many of whom will be mothers, ${ }^{9}$ the current review will draw together research considering maternal BPD. The aim is to systematically synthesise the findings of this research, in order to provide a better understanding of the consequences of maternal BPD.

Two questions are explored:

1. Are there deficits and difficulties in the parenting of mothers with $\mathrm{BPD}$ ?

2. What difficulties are experienced by children of mothers with BPD?

\section{STUDY SELECTION AND ANALYSIS}

Searches were conducted on PsycINFO and MEDLINE.
The search string was: "child*" AND ("borderline personality disorder" OR "emotionally unstable personality disorder"). Figure 1 depicts the search process at the final date for checking: 10 July 2014.

Non-English language articles were removed, leaving 3405 articles. After removing duplicates, there remained 2579. In stage 1, titles and abstracts were read against inclusion/exclusion criteria by $L P$, and a random 10\% were re-rated by an independent researcher. Agreement was $97.8 \%$. Disagreements were resolved on discussion.

This resulted in removal of 2510 articles, leaving 70 . At stage 2, each full paper was scrutinised against the inclusion/exclusion criteria (table 1).

Consequently, 54 papers were excluded (the reasons are summarised in table 2).

This left 17 papers that satisfied the inclusion/exclusion criteria. Reference lists were scrutinised for titles relevant to the review. This revealed no further papers.

Eight prominent authors were contacted, and asked to identify any additional studies, but none were found.

\section{Quality appraisal}

The Strengthening the Reporting of Observational studies in Epidemiology (STROBE) checklist ${ }^{10}$ is widely accepted as a tool for improving the quality of reporting of observational studies. ${ }^{11}$ The crosssectional variant lists 22 areas that are required for highest quality reporting of cross-sectional research. For this review, each area was rated on a five-point scale, and scores averaged to provide a total score. Four papers were categorised as 'average to above average', and 13 as 'above average to good' (terms based on the Jadad scale, ${ }^{12}$ which ranges from 0 (bad) to 5 (good); table 3).

Five randomly selected articles were re-scored by an independent rater. Inter-rater reliability was assessed using Spearman's correlation, giving a strong, positive correlation between quality ratings, $r_{s}=0.95, n=5$, $p=0.014$. The primary researcher's ratings were, therefore, accepted.

\section{FINDINGS}

\section{Maternal BPD and parenting}

Fourteen studies assessed parenting (table 4). Across the age range, these studies showed that mothers with BPD were parenting in the 


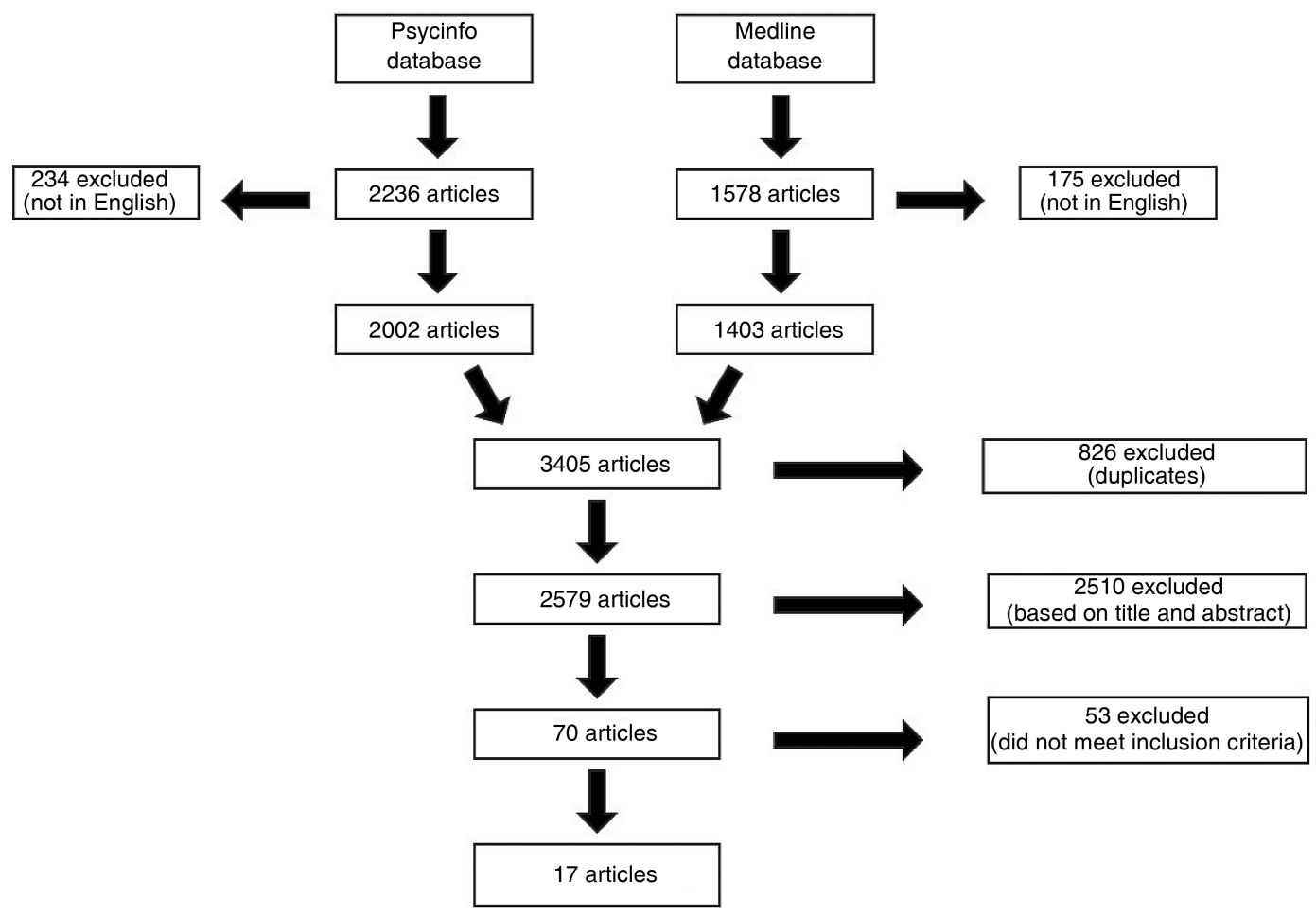

Figure 1 Search process.

context of many factors that are known to put parenting and children's mental health at risk. All studies that explored parental depression showed this to be significantly elevated in mothers with BPD, compared with a range of control groups. ${ }^{13-16}$ Feldman et a ${ }^{17}$ noted higher drug and alcohol abuse in parents with BPD (present in 88\%), and White et $a l^{18}$ noted that their sample of parents with BPD used more alcohol during pregnancy.

Some studies ${ }^{15}$ i9 noted that mothers with BPD were more likely than control groups to be parenting without the support of a partner, or within a household that frequently changed in its composition. ${ }^{17}$ This study also noted that children of BPD parents had experienced more changes in school, and more non-maternal care than controls.

Parental mental health also made its impact felt in other ways: Feldman et $a l^{17}$ showed that children of parents with BPD were at risk of witnessing parental suicide attempts, with $24 \%$ of the sample (mean age 11 years) having witnessed a maternal attempt, and 19\% having witnessed a paternal attempt.

The impacts of BPD on parenting are now presented by age of child: babies and young children; older children.

\section{Babies and young children}

Parenting in the context of BPD is not well understood, but perhaps the greatest attention has been devoted to the newborn and toddler age group. All studies of this age group conclude that mothers with BPD parent differently, on average, to a range of control samples.

\section{Interaction style}

White et $a l^{18}$ studied mothers with BPD, major depressive disorder (MDD) and healthy controls, in interaction with their 3-month-old infants. Mothers with BPD smiled less, touched and imitated their infants less and played fewer games with their babies. Lack of sensitivity in interactions with offspring is a recurring theme. Crandell et al ${ }^{20}$ observed mothers of 2-month-old infants in face-to-face interaction with their child. Compared with healthy controls, mothers with BPD were less sensitive in their interactions, and more intrusive. Observers subsequently rated their interactions as less 'satisfying' and 'engaged'. Similarly, Newman et $a l^{13}$ rated mothers with BPD of 16-month-olds as less sensitive than healthy controls, and Hobson et $a^{21}$ also found their mothers with BPD to be more 'intrusively insensitive' in their interactions with their 1-year-olds, compared with healthy controls, and these differences remained once demographic differences between the groups were controlled. Kiel et $a l^{22}$ found that, in comparison with healthy control mothers, mothers with BPD showed less positive affect in response to infant distress, and took longer to do so. As infant distress increased in duration, mothers with BPD were increasingly likely to show insensitive behaviour towards their child. These differences remained even when group differences in anxiety and depression were controlled. Hobson et $a^{23}$ also explored affective communication, this time in mothers with BPD of toddlers. This was found to be disrupted, in comparison to a healthy control group and a depressed control group. Mothers with BPD were also more likely to exhibit a 'fear/disorientation' response to their child's attachment bids, a pattern that has been linked to disorganised attachment in the child. ${ }^{24}$ Finally, musicologists recorded interactions between mothers and their 3-month-old infants. ${ }^{25}$ They found that, in comparison with healthy controls, interactions where the mother had BPD differed in temporal qualities and musical organisation'. Mothers with BPD paused longer and used more non-vocal sounds than controls.

\section{Emotion recognition}

Ability to identify infants' emotions was disrupted in BPD mothers of children aged 3-14 months. ${ }^{26}$ Compared with healthy controls, mothers with BPD were less accurate at identifying emotions in photographs of their own and unfamiliar children. In particular, they were prone to labelling neutral expressions as 'sad'. This sample of mothers was also likely to self-report overprotection of their child.

\section{Activity structuring}

On a pragmatic level, mothers with BPD were found to be less good at structuring their children's activities, in comparison with healthy controls. ${ }^{27}$ 
Table 1 Inclusion and exclusion criteria

\begin{tabular}{|c|c|c|}
\hline Type & Inclusion criteria & Exclusion criteria \\
\hline \multirow[t]{4}{*}{ Sample } & $\begin{array}{l}\text { Mothers must have been diagnosed with BPD using standardised assessment procedures, such } \\
\text { as the Structured Clinical Interview for DSM-IV }\left(\text { SCID-II; First et } a l^{34}\right) \text {, the Revised Diagnostic } \\
\left.\text { Interview for Borderlines (DIB-R; Zanarini, et }\left.a\right|^{35}\right) \text {, the Structured Interview for DSM-IV Personality } \\
\left(\text { SIDP-IV; Pfohl et }\left.a\right|^{36} \text { ) or the Borderline Evaluation of Severity over Time (BEST; Pfohl et }\left.a\right|^{37} \text { ). }\right. \\
\text { Older studies using diagnostic techniques based on earlier editions of the DSM also acceptable }\end{array}$ & Diagnosis by any non-standardised assessment procedures \\
\hline & Mothers must be the primary caregiver to their child/children & Mothers not the primary caregiver to their children \\
\hline & Mothers must be aged 18 or over & Mothers aged under 18 \\
\hline & Children must be aged 18 or under & Children aged over 18 \\
\hline Procedure & Studies must measure factors influencing the mother's parenting and/or her child's functioning & Study does not measure these factors \\
\hline \multirow[t]{4}{*}{ Style } & Studies must be written in English & Studies written in any other language \\
\hline & Studies must present outcome data & $\begin{array}{l}\text { Study does not present unique outcome data (eg, reviews, } \\
\text { commentaries, opinion pieces, books or chapters) }\end{array}$ \\
\hline & Studies must be from peer-reviewed journals & $\begin{array}{l}\text { Study is not peer-reviewed. Therefore, dissertations were } \\
\text { excluded }\end{array}$ \\
\hline & Studies must be quantitative in design & Case studies and qualitative papers were excluded \\
\hline
\end{tabular}

BPD, borderline personality disorder; DSM, Diagnostic and Statistical Manual of Mental Disorders.

\section{Parenting stress/self-competence}

Unsurprisingly, given the results described above, mothers with BPD, of children in this age group have been shown to self-report higher parenting stress, ${ }^{15} 26$ lower competence, ${ }^{27} 26$ and lower satisfaction in the parenting role ${ }^{13}$ than control parents.

\section{Older children}

\section{Family environment}

Using the Family Environment Scale, ${ }^{28}$ Feldman et $a{ }^{17}$ showed that mothers with BPD rated their family as lower in cohesion and organisation, and higher on conflict than the control group, which comprised mothers with other types of personality disorder. Children in this study (mean 11 years) were also more likely to rate their family as low in cohesion and expressiveness if their parent was diagnosed with BPD as opposed to another personality disorder. Similarly, Herr et $a^{29}$ found that BPD symptoms in mothers were correlated with ratings of maternal hostility given by their 15 -year-old offspring. Feldman et $\mathrm{al}^{17}$ concurred, finding that verbal abuse, physical abuse and witnessing of violence were common in their sample of children of mothers with BPD, even in comparison with children whose parents had other personality disorders.

\section{Mind-mindedness}

Schacht et $a^{16}$ explored mind-mindedness (parental ability and willingness to think about their child's mental state ${ }^{30}$ in parents of children aged 39-61 months). They found evidence of reduced mindmindedness in interviews with mothers with $\mathrm{BPD}$, in comparison with

Table 2 Reasons for exclusion following full-text examination

\begin{tabular}{ll}
\hline Reason for exclusion & $\begin{array}{l}\text { Number } \\
\text { excluded }\end{array}$ \\
\hline $\begin{array}{l}\text { Non-peer-reviewed studies, or reviews or commentary pieces } \\
\text { Investigated the parents or siblings of individuals with BPD (but } \\
\text { not offspring) }\end{array}$ & 19 \\
$\begin{array}{l}\text { Investigated several different personality disorders, and did not } \\
\text { present specific results for those with BPD }\end{array}$ & 7 \\
$\begin{array}{l}\text { Investigated mothers with BPD, or their children, but did not } \\
\text { examine parenting or children's outcomes }\end{array}$ & 7 \\
$\begin{array}{l}\text { Only measured borderline features, no diagnosis of BPD } \\
\text { Children were aged over 18 }\end{array}$ & 5 \\
Case studies & 3 \\
\hline
\end{tabular}

$\mathrm{BPD}$, borderline personality disorder. healthy controls, a difference that remained once maternal depression was controlled.

\section{Overprotection}

Two studies found that mothers with BPD scored higher on a measure of overprotection of children. Children (mean age 11 years) of mothers with BPD rated their mothers as less encouraging of independence than children whose mothers had other personality disorders. ${ }^{17}$ Similarly, mothers with BPD were reported to be more overprotective by their children aged 11-18 years, in comparison with healthy controls and controls with depressive illness and other personality disorders. ${ }^{19} \mathrm{It}$ should be noted, however, that children of mothers with BPD might be living in environments that are more risky than average children, and that this higher reported overprotection might be advantageous in these conditions.

\section{Parenting stress/satisfaction}

Finally, given the differences in parenting reported above, it is not surprising that Herr et a $\left.\right|^{29}$ noted chronic stress in the relationship between mothers with high levels of BPD symptomatology and their 15-year-old offspring, and Feldman et al found extremely low selfreported satisfaction with their family (at the 1st centile) in mothers with BPD. ${ }^{19}$

\section{Influence of maternal BPD on children's outcomes}

Twelve papers measured the association between maternal BPD and child outcomes (see table 4). As above, the outcomes are reported separately for babies/toddlers and for older children.

Table 3 Five-point rating system developed to score the STROBE checklist

\begin{tabular}{ll}
\hline Rating & Explanation \\
\hline 1 & $\begin{array}{l}\text { Weak, main points missing, with little thought or consideration given to } \\
\text { important factors }\end{array}$ \\
2 & $\begin{array}{l}\text { Below average, with some but not all main points included, some } \\
\text { information still missing }\end{array}$ \\
3 & $\begin{array}{l}\text { Average, acceptable amount of information on main areas given, but } \\
\text { additional relevant information that would have made the section stronger is } \\
\text { missing } \\
4\end{array}$ \\
$\begin{array}{l}\text { Above average, all main areas considered and discussed in depth, with a } \\
\text { few pieces of less important information missing } \\
\text { Good, all areas carefully considered and discussed, very little missing }\end{array}$ \\
\hline
\end{tabular}


Table 4 Summary of studies investigating the impact of maternal BPD on parenting, and on children

\section{Number of mothers}

Study

With Healthy

ages)

Abela et al ${ }^{32}$

(6-14 years)

-

With other

$-$

20

\section{of of healthy}

mothers control
with BPD

mothers

Of mothers with
other disorders

How BPD in the

mother was diagnosed Measures

120 from mothers SCID-II

with MDD

SCID-II

47 from mothers SCID-II

Barnow et al ${ }^{19}$

(11-18 years)

116

36 mothers with

depression

28 mothers with

other personality

disorders

Crandell et $a l^{20}$

(2 months)

$8 \quad 12$

$-$

12

$-$

11 from mothers

31 from mothers

with Cluster C PDs

Completion of the questionnaire and full interview section of the SCID-II

Newman ${ }^{15}$

(3-36 months)

Delavenne

et $\mathrm{al}^{25}$

(3 months)

1 years
$-$

SIDP-IV

Zanarini Rating Scale for Borderline Personality Disorder

PDS, BDI, Alcohol Use Disorders dentification Test, CTO, DERS, ECRS, PSI-SF, and PACOTIS

23 from mothers

with other

personality

disorders used software to define interaction phrases
Verbal interviews, K-SADS, CASQ, CRSQ

SEQ, CDAS-R, CDEQ, IPPA and RSSC

iagnostic Expert System for Psychiatric Disorders, SSAGA, and the Children Diagnostic Interview for Psychiatric Disorder. All given the CBCL, TCI, EMBU, YSR, and the Rosenberg Self-Worth Scale. Mothers interviewed using the Diagnostic Expert System for Psychiatric Disorders, and SSAGA

Interactions between mother and baby ated using the global ratings for mother-

Quality

out of 5 Summary of findings

Parental BPD was significantly related to

children having more depressive

symptoms, negative attributional style,

dysfunctional attitudes, insecure

attachment style, and excessive

reassurance seeking. $45 \%$ of these children

had experienced a major depressive

episode

More comorbidity in the mothers with

BPD. Described by their children as being

overprotective. Children whose mothers

had BPD had higher harm avoidance, more attention problems, more delinquency and

aggression, social problems, and more

self-ratings of depression, anxiety,

emotional problems, suicidal tendencies

and lower self-esteem

Mothers with BPD relate to their infants in an intrusively insensitive manner, and their mother-infant interactions were scored as less satisfying by an objective rater. During the mother's non-response stage, infants of mothers with BPD had more dazed looks. After this stage, they showed less positive affect

Mothers with BPD reported higher levels of depression and parenting stress

Used vocal recordings of interactions and

Mothers with BPD had more fragmented interactions with their infants

characterised by longer pauses, fewer interactional phrases, and more non-vocal sounds to fill gaps. Infants of mothers with BPD vocalised less than control infants. Their vocalisations were also shorter

Mothers with BPD were less accurate when identifying emotions in infants. Higher scores for depression, total emotional dysregulation, and parenting stress. Lower perception of their own parenting competence

Mothers with BPD scored significantly lower than control mothers on measures of cohesion and organisation, and had lower satisfaction with their families. Children of mothers with BPD were exposed to more parental suicide attempts and reported low 


\begin{tabular}{|c|c|c|c|c|c|c|c|c|c|c|}
\hline \multirow[b]{2}{*}{$\begin{array}{l}\text { Study } \\
\text { (children's } \\
\text { ages) }\end{array}$} & \multicolumn{3}{|c|}{ Number of mothers } & \multicolumn{3}{|c|}{ Number of children } & \multirow[b]{2}{*}{$\begin{array}{l}\text { How BPD in the } \\
\text { mother was diagnosed }\end{array}$} & \multirow[b]{2}{*}{ Measures } & \multirow[b]{2}{*}{$\begin{array}{l}\text { Quality } \\
\text { rating } \\
\text { out of } 5\end{array}$} & \multirow[b]{2}{*}{ Summary of findings } \\
\hline & $\begin{array}{l}\text { With } \\
\text { BPD }\end{array}$ & $\begin{array}{l}\text { Healthy } \\
\text { controls }\end{array}$ & $\begin{array}{l}\text { With other } \\
\text { disorders }\end{array}$ & $\begin{array}{l}\text { Of } \\
\text { mothers } \\
\text { with BPD }\end{array}$ & $\begin{array}{l}\text { Of healthy } \\
\text { control } \\
\text { mothers }\end{array}$ & $\begin{array}{l}\text { Of mothers with } \\
\text { other disorders }\end{array}$ & & & & \\
\hline & & & & & & & & & & $\begin{array}{l}\text { levels of familial satisfaction, } \\
\text { independence and expressiveness }\end{array}$ \\
\hline $\begin{array}{l}\text { Gratz et al }{ }^{14} \\
\text { (12-23 months) }\end{array}$ & 23 & 78 & - & 23 & 78 & - & DIB-R, BEST & $\begin{array}{l}\text { Infant behaviours and the strange situation } \\
\text { scenario were videotaped and coded using } \\
\text { the AFFEX coding system, alongside using } \\
\text { DERS, AIM, DASS }\end{array}$ & 4.4 & $\begin{array}{l}\text { More depressive symptoms in mothers } \\
\text { with BPD. Higher levels of maternal } \\
\text { intensity and reactivity, found in those } \\
\text { with BPD, were linked with lower } \\
\text { self-focused emotion regulation, blunted } \\
\text { fear and more anger in their infants }\end{array}$ \\
\hline $\begin{array}{l}\text { Herr et al }{ }^{29} \\
\text { (15 years) }\end{array}$ & 70 & 461 & $\begin{array}{l}354 \text { with either } \\
\text { MDD, Depressive } \\
\text { Disorder, or both }\end{array}$ & 70 & 461 & $\begin{array}{l}354 \text { from mothers } \\
\text { with either MDD, } \\
\text { Depressive } \\
\text { Disorder, or both }\end{array}$ & SCID-II & $\begin{array}{l}\text { KSADS-E, BDI, YCS, SPPA, Teacher Report } \\
\text { of Youth Interpersonal Functioning, } \\
\text { Bartholomew Attachment Prototypes } \\
\text { Questionnaire, PPQ }\end{array}$ & 4.2 & $\begin{array}{l}\text { Children of mothers with BPD found it hard } \\
\text { to make friends and be socially accepted. } \\
\text { Also had more fearful attachment } \\
\text { cognitions. Rated their mothers as more } \\
\text { likely to be hostile }\end{array}$ \\
\hline $\begin{array}{l}\text { Hobson et a }\left.\right|^{21} \\
\text { (12 months) }\end{array}$ & 10 & 22 & - & 10 & 22 & - & SCID-II & $\begin{array}{l}\text { Rated interactions using the global ratings } \\
\text { for mother-infant interactions (Murray et al, } \\
\text { 1996) }\end{array}$ & 4.4 & $\begin{array}{l}\text { Mothers with BPD were found to be more } \\
\text { intrusively insensitive. Infants whose } \\
\text { mothers had BPD displayed less } \\
\text { availability for positive engagement, lower } \\
\text { behavioural organisation and mood state, } \\
\text { and they gave fewer positive looks to a } \\
\text { stranger }\end{array}$ \\
\hline $\begin{array}{l}\text { Hobson et a }\left.\right|^{23} \\
\text { (Unclear. Circa } \\
1-2 \text { years; } \\
\text { average age } \\
69 \text { weeks) }\end{array}$ & 13 & 31 & $\begin{array}{l}15 \text { mothers with } \\
\text { depression }\end{array}$ & 13 & 31 & $\begin{array}{l}15 \text { from mothers } \\
\text { with depression }\end{array}$ & SCID-II & AMBIANCE & 4 & $\begin{array}{l}\text { Mothers with BPD were more likely to } \\
\text { have disrupted affective communication } \\
\text { with their infants. Showed more } \\
\text { disorientation and fear during infants' } \\
\text { attachment bids }\end{array}$ \\
\hline $\begin{array}{l}\text { Kiel et al }{ }^{22} \\
\text { (12-23 months) }\end{array}$ & 22 & 77 & - & 22 & 77 & - & BEST & $\begin{array}{l}\text { DERS, DASS, maternal affective and } \\
\text { behavioural expressions were coded }\end{array}$ & 4 & $\begin{array}{l}\text { Mothers with BPD had more emotion } \\
\text { dysregulation. Took longer time to display } \\
\text { positive affect in response to infant } \\
\text { distress. Mothers with BPD were more } \\
\text { likely to respond insensitively when infant } \\
\text { distress continued }\end{array}$ \\
\hline $\begin{array}{l}\text { Macfie and } \\
\text { Swan }^{31}(4- \\
7 \text { years) }\end{array}$ & - & - & - & 30 & 30 & - & SCID-II & $\begin{array}{l}\text { PPVT-III, ASCT, the MacArthur Story Stem } \\
\text { Battery, coded using the same systems as } \\
\text { Macfie et al }{ }^{39}\end{array}$ & 4.4 & $\begin{array}{l}\text { Children of mothers with BPD expressed } \\
\text { more fear of abandonment, role reversal } \\
\text { and more negative expectations of parent- } \\
\text { child relationships in a role-play situation. } \\
\text { More likely to represent themselves as } \\
\text { incongruent and shameful. More confusion } \\
\text { between fantasy and reality }\end{array}$ \\
\hline $\begin{array}{l}\text { Newman et } \mathrm{al}^{13} \\
\text { (mean } \\
16 \text { months) }\end{array}$ & 14 & 20 & - & 14 & 20 & - & $\begin{array}{l}\text { Independent clinical } \\
\text { diagnosis of BPD, } \\
\text { meeting DSM-IV criteria } \\
\text { for BPD, and DIB-R }\end{array}$ & Video interactions coded using EA scales & 4 & $\begin{array}{l}\text { Mothers with BPD scored significantly } \\
\text { higher on all SCL-90R psychopathology } \\
\text { indices and on the EPDS. Mothers with } \\
\text { BPD were less sensitive, and reported less } \\
\text { satisfaction and more incompetence in } \\
\text { their parenting. Infants whose mothers had } \\
\text { BPD were less responsive to the mother, } \\
\text { and less eager to engage with her }\end{array}$ \\
\hline
\end{tabular}


Table 4 Continued

\begin{tabular}{|c|c|c|c|c|c|c|c|c|c|c|}
\hline \multirow[b]{2}{*}{$\begin{array}{l}\text { Study } \\
\text { (children's } \\
\text { ages) }\end{array}$} & \multicolumn{3}{|c|}{ Number of mothers } & \multicolumn{3}{|c|}{ Number of children } & \multirow[b]{2}{*}{$\begin{array}{l}\text { How BPD in the } \\
\text { mother was diagnosed }\end{array}$} & \multirow[b]{2}{*}{ Measures } & \multirow[b]{2}{*}{$\begin{array}{l}\text { Ouality } \\
\text { rating } \\
\text { out of } 5\end{array}$} & \multirow[b]{2}{*}{ Summary of findings } \\
\hline & $\begin{array}{l}\text { With } \\
\text { BPD }\end{array}$ & $\begin{array}{l}\text { Healthy } \\
\text { controls }\end{array}$ & $\begin{array}{l}\text { With other } \\
\text { disorders }\end{array}$ & $\begin{array}{l}\text { Of } \\
\text { mothers } \\
\text { with BPD }\end{array}$ & $\begin{array}{l}\text { Of healthy } \\
\text { control } \\
\text { mothers }\end{array}$ & $\begin{array}{l}\text { Of mothers with } \\
\text { other disorders }\end{array}$ & & & & \\
\hline $\begin{array}{l}\text { Schacht et al }{ }^{16} \\
\text { (39-61 months) }\end{array}$ & 20 & 19 & - & 20 & 19 & - & $\begin{array}{l}\text { Mothers needed to } \\
\text { attract a BPD diagnosis } \\
\text { on at least one of two } \\
\text { administrations of } \\
\text { SCID-II }\end{array}$ & $\begin{array}{l}\text { Mothers given BDI, Meins and } \\
\text { Fernyhough's (2010) brief interview } \\
\text { measure for mind-mindedness. Children } \\
\text { given SCQ, BPVS-II, false-belief tasks, } \\
\text { affective-labelling task, and a modified } \\
\text { version of the causes of emotions interview }\end{array}$ & 4.2 & $\begin{array}{l}\text { Mothers with BPD were more likely to } \\
\text { report depressive symptoms. They also } \\
\text { used significantly fewer mind-related } \\
\text { comments to describe their children. } \\
\text { Children of mothers with BPD struggled to } \\
\text { identify and describe causes of emotion, } \\
\text { and had less understanding of mental } \\
\text { states, doing less well in the Theory of } \\
\text { Mind tasks }\end{array}$ \\
\hline $\begin{array}{l}\text { Weiss et } a^{33} \\
(4+. \text { Mean } \\
\text { approximately } \\
11 \text { years) }\end{array}$ & 9 & - & $\begin{array}{l}14 \text { mothers with } \\
\text { other personality } \\
\text { disorders }\end{array}$ & 21 & - & $\begin{array}{l}23 \text { from mothers } \\
\text { with other } \\
\text { personality } \\
\text { disorders }\end{array}$ & DIB-R & FTRI, KSADS-E, CGAS and CDIB & 4 & $\begin{array}{l}\text { Children of mothers with BPD had } \\
\text { significantly more general } \\
\text { psychopathology. Both groups had history } \\
\text { of trauma }\end{array}$ \\
\hline $\begin{array}{l}\text { White et } a l^{18} \\
\text { (c. } 3 \text { months) }\end{array}$ & 17 & 25 & $\begin{array}{l}25 \text { mothers with } \\
\text { MDD and } 20 \\
\text { mothers with } \\
\text { BPD comorbid } \\
\text { with MDD }\end{array}$ & 17 & 25 & $\begin{array}{l}25 \text { from mothers } \\
\text { with MDD, } 20 \text { from } \\
\text { mothers with } \\
\text { comorbid MDD } \\
\text { and BPD }\end{array}$ & SCID-IV and DIB-R & $\begin{array}{l}\text { BDI and BAI. Videotaped interactions coded } \\
\text { using the Interaction Rating Scale. Children } \\
\text { given the IBQ-R }\end{array}$ & 4.2 & $\begin{array}{l}\text { Women with BPD, and those with } \\
\text { comorbid MDD, consumed more alcohol } \\
\text { during pregnancy than healthy controls. } \\
\text { Smiled less at their infants than healthy } \\
\text { controls. Mothers with BPD also touched } \\
\text { their infants less, played fewer games } \\
\text { with them, and imitated them less. Infants } \\
\text { of mothers with BPD had higher levels of } \\
\text { fear, were less soothable, and were } \\
\text { classed as having higher environmental } \\
\text { risk. Less frequent smiling and vocalisation }\end{array}$ \\
\hline
\end{tabular}

AAl, Adult Attachment Interview; AFFEX, System for Identifying Affect Expression by Holistic Judgement; AIM, Affect Intensity Measure; AMBIANCE, Atypical Maternal Behaviour Instrument for Assessment and Classification; ASCT,

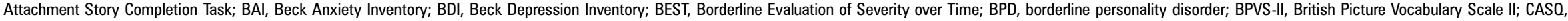

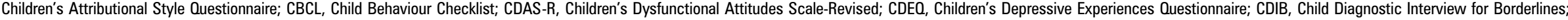

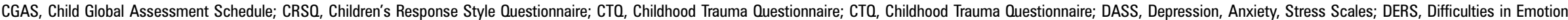

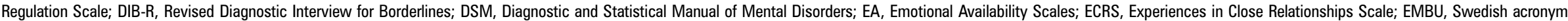

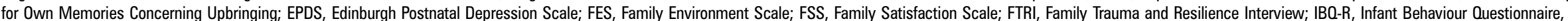

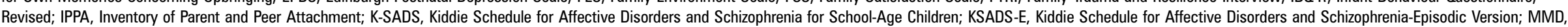

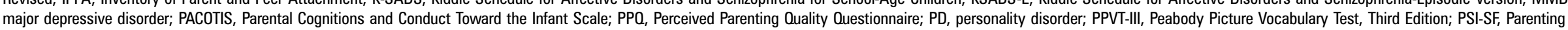
Stress Index Short Form; RSSC, Reassurance-Seeking Scale for Children; SCID-II, Structured Clinical Interview for DSM-IV; SCL-90-R, Symptom Checklist 90 Revised; SCQ, Social Communication Questionnaire; SEQ, Children's Self-Esteem

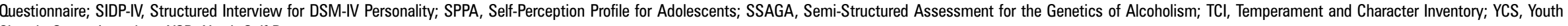
Chronic Stress Interview; YSR, Youth Self-Report. 


\section{Babies/toddlers}

Across five studies, babies/toddlers of mothers with BPD behaved differently to those of control mothers. Crandell et $a^{20}$ found that when exposed to a $90 \mathrm{~s}$ 'still-face' challenge, 2-month-old infants of mothers with BPD were more likely to look away, or to look dazed than children of healthy controls. In a standard face-to-face interaction with their mother, children of mothers with BPD showed less positive affect, and again, more dazed looks. In similar studies of face-to-face interactions between mothers and their infant children, children of mothers with BPD were shown to smile less, ${ }^{18}$ vocalise less, ${ }^{18}{ }^{25}$ avert their gaze more, appear more fearful and be less soothable, ${ }^{18}$ be less responsive to mothers' bids for interaction, and show less optimally 'involving' behaviours towards their mothers than control mothers. ${ }^{27}$ They also displayed lower 'availability for positive engagement' with and fewer positive looks towards a stranger, and had lower 'behavioural organisation' and mood state. ${ }^{21}$

\section{Older children}

\section{Cognitive and behavioural risk factors}

Older children of parents with BPD showed a range of cognitive and behavioural risk factors in comparison with control children. Herr et al ${ }^{29}$ found that maternal BPD symptoms were negatively correlated with Harter social acceptance scores, and ability to make close friends in their 15-year-old sample, and that this relationship held even after maternal depression was controlled. Schacht et $a l^{16}$ found that preschool-aged children of women with BPD had poorer theory of mind when given a false-belief task, and were poorer at both labelling pictures of emotional faces and identifying possible causes of the depicted emotions. Macfie and Swan ${ }^{31}$ found that their children aged 4-7 years of mothers with BPD displayed more negative self-representations, more fantasy-proneness and fantasy-reality confusion, lower narrative coherence and more intrusion of traumatic material when participating in a series of role-play scenarios, when compared with children of healthy mothers. Abela et a/ ${ }^{32}$ found their children aged 6-14 years of mothers with BPD to have a more negative attribution style, more dysfunctional attitudes, a more ruminative response style, engage in more reassurance-seeking, and have higher levels of self-criticism than a sample of children of depressed mothers. Finally, in the study by Barnow et $\mathrm{al}^{19}{ }^{19}$ children (aged 11-18 years) showed excessive harm-avoidance, in comparison with children of depressed mothers and healthy mothers.

\section{Parent-child relationships}

As well as these elevated cognitive and behavioural risk factors, children seem to have a higher risk of problematic relationships with their parents with BPD. Four studies showed that children of mothers with BPD had elevated instances of disrupted attachment styles. ${ }^{21} 293132$ Additionally, in role-play tasks, children of mothers with BPD laged 47 years) showed excessive role-reversal, ${ }^{31}$ and fear of abandonment in their relationships with their parents, and more negative expectations of these relationships. Interestingly, Gratz et $a l^{14}$ reported that although there was no direct relationship between maternal BPD symptoms and infant emotion regulation in their sample, there was an indirect relationship, which was mediated by maternal emotional dysfunction, and that this was particularly the case for the large proportion of children in their sample who were classified as having an insecure-resistant attachment style.

\section{Mental health outcomes}

In almost all instances where mental health outcomes were explored, children of parents with BPD fared worse than control children, even when these control children had parents with significant mental health difficulties, for example, Weiss et al ${ }^{33}$ found that children of mothers with BPD (mean age around 11 years) had lower Child Global Assessment Schedule (CGAS) scores than children of mothers with other personality disorders, and that the mean of these scores was in the 'non-functional' range. The one exception was the study by Abela et $a l_{,}^{32}$ which did not find increased difficulties with self-esteem or dependency in children aged 6-14 years of mothers with BPD, compared with children of depressed mothers. It should be noted that lack of power (there were only 20 mothers with BPD) in this study could have accounted for this null finding.

Three studies that explored symptoms of emotional disorders found that these were higher in children of parents with BPD compared with control groups: Barnow et al compared children aged 11-18 years of mothers with BPD with children of mothers with depression, and mothers with other personality disorders, and found the children of mothers with BPD to have signs of higher levels of emotional disorder and of suicidal ideation. ${ }^{21}$ Indeed, $9 \%$ of children whose mothers had BPD had already attempted suicide, compared with $2 \%$ of children of healthy mothers. Abela et a/ ${ }^{32}$ studied children aged 6-14 years and found that those with a mother with BPD had experienced more depression (45\% had suffered a major depressive episode), than a sample of children whose mothers were currently depressed. This study explored a number of potential cognitive and behavioural risk factors in children (see above) and found that these partly mediated the relationship between maternal BPD and children's depression. Finally, Herr et $\mathrm{a}^{29}$ found that symptoms of BPD in mothers were positively associated with depression in their 15-year-old youth, although in this instance, this relationship disappeared when maternal depression was controlled.

Two studies explored the relationship between maternal BPD and children's externalising symptoms. In both cases, there was a positive association. Weiss et $a l^{\beta 3}$ reported that children (with a mean age of 11) whose mother had BPD, were more likely to have a behavioural disorder or attention deficit disorder than the children in the control group, whose parents had a range of other personality disorders (but not BPD). Barnow et $a l^{19}$ also found more parent-reported symptoms of (11-18 years old) children's behavioural problems in their sample of mothers with BPD, in comparison with children of healthy controls.

\section{CONCLUSIONS AND CLINICAL IMPLICATIONS}

In studies employing a range of designs and comparison groups, and all of reasonable quality, mothers' BPD diagnosis was clearly associated with differences in parenting. In the studies of early childhood, most of which focussed on mother-child interactions, maternal BPD was associated with reduced sensitivity and increased intrusivity towards the child. $^{13} 20-22$ This is, perhaps, not surprising, given the finding that mothers with BPD found it difficult to correctly identify emotions in photographs of both their own and strangers' children. ${ }^{26}$ Mothers with BPD also found it more difficult to structure their young child's activities, $^{13}$ and in later childhood were rated as having poorer levels of family organisation. ${ }^{17}$ The family environment where mothers had BPD was characterised by high levels of hostility, ${ }^{17} 29$ and low levels of cohesion, ${ }^{17}$ according to both parent and child reportings. Mothers with BPD were reported to show high levels of overprotection towards their children ${ }^{17}{ }^{19}$ but to have lower levels of mind-mindedness, ${ }^{16}$ that is, a reduced ability to reflect on their child's internal world.

Given these difficulties in parenting experienced by mothers with BPD, it is perhaps unsurprising that they reported feeling less competence $^{1326}$ and satisfaction ${ }^{27} 17$ in the parenting role. In a number of studies, they also found parenting to be a very stressful task. ${ }^{152629}$

The children of mothers with BPD experience a range of negative outcomes. In infancy, they appear to experience interactions with their mother as less satisfying, ${ }^{20}$ showing signs of less positive affect, $^{18} 2021$ more looking away, ${ }^{18} 20$ more dazed looks ${ }^{20}$ and fewer 
vocalisations. ${ }^{18} 25$ Subsequently, these children experience a range of cognitive-behavioural risk factors. Compared with control children, they had more difficulties with friendships, ${ }^{29}$ poorer theory of mind, ${ }^{16}$ difficulties labelling and understanding the causes of common emotions, ${ }^{16}$ increased fantasy proneness and difficulty distinguishing fantasy and reality, ${ }^{31}$ increased negative attributional style, dysfunctional attitudes, rumination and self-criticism. ${ }^{32}$ They also experience difficulties in the mother-child relationship, with four studies reporting high levels of disrupted attachment styles, ${ }^{21} 293132$ and in role-play scenarios elevated levels of role-reversal with parents, fear of abandonment, and negative expectations of parents. ${ }^{31}$ These factors are known to put children at risk of poor mental health outcomes, and indeed, this appears to be the case. Children of mothers with BPD had poorer mental health than control groups, showing substantially elevated levels of depression, ${ }^{19} 2932$ suicidality, ${ }^{19}$ fearfulness, ${ }^{18} 29$ behaviour problems ${ }^{19} 33$ and attention deficit disorder. ${ }^{33}$

Most notably, many studies included parents with other diagnoses as control groups, typically other severe presentations, such as MDD and other personality disorders. In most instances, mothers with BPD (and their children) had greater difficult and poorer outcomes than any of these groups, underscoring the particularly severe difficulties that are faced by these mothers and their children.

But, can a causal relationship between BPD and impaired parenting, and subsequently between parenting and child outcome be assumed? Given the difficult circumstances in which mothers with BPD are often parenting (increased likelihood of lone-parenting, ${ }^{15}{ }^{19}$ depression, ${ }^{13-16}{ }^{26}$ substance misuse, ${ }^{17}{ }^{18}$ we must consider the possibility that it is these factors, rather than BPD that cause the poor outcomes for their children. However, many of the studies reported here controlled for maternal depression and/or demographic factors, and in almost every instance, the relationship between BPD and impaired parenting, or BPD and child outcomes, was upheld. Unfortunately, few studies have examined both parenting risks and child outcomes, and explored the mediating role of the former. However, in the handful of studies that did this, it was apparent that the relationship between parent and child mental health was mediated by parenting difficulties.

The current systematic review is subject to some limitations. First, owing to a lack of resource for translation, it excluded all papers that were not in English. Second, although all studies were deemed to be of a reasonable standard, all were subject to some risk of bias. In particular, all were cross-sectional in design, which limits the conclusions that may be drawn. Similarly, although all studies made some attempt to confirm a diagnosis of BPD in participants, in some cases, ${ }^{14} 2229$ this was achieved only by means of self-report questionnaire measures, which is not an optimally valid approach. Similarly, parents were often the primary reporter on children's outcomes, which is likely to have introduced a bias. Almost all the studies were very small (see table 4), meaning that they were probably underpowered to detect smaller group differences (although it should be noted that most studies found significance between groups on almost all their outcome measures). However, the very small samples of mothers with BPD that were present in most of the studies will have had an impact on generalisability of the findings. The risk of publication bias is probably quite high, given the small sample sizes in the field, and the consequent lack of power likely in many studies. Finally, it is not clear whether the studies reported here employed samples that are highly representative of the diverse population of mothers with BPD. Most employed clinical samples, which is likely to be over-representative of the severe end of the disorder. It should be noted that all these studies represent the 'average' parent with BPD, and it is likely that many such parents actually manage very well and have children with good outcomes.

The findings of this review show how very difficult parenting is for mothers with a diagnosis of BPD. These difficulties are probably more severe than for families where a parent has MDD or another personality disorder. Furthermore, it seems likely that if these mothers are not supported in the parenting role, their children are at risk for a range of poor outcomes. While interventions exist for women with $\mathrm{BPD},{ }^{9}$ there are currently no interventions that aim to reduce the risk to their children. These families do not deserve to be as overlooked as they have been, as there is evidence, even though it is limited, that they are in particular need of help.

Disclaimer This report is independent research arising from an NIHR Career Development Award supported by the National Institute for Health Research. The views expressed in this publication are those of the authors and not necessarily those of the NHS, the National Institute for Health Research of the Department of Health.

Competing interests None declared

doi:10.1136/eb-2015-102163

Received 15 July 2015; Accepted 16 June 2015

\section{REFERENCES}

1. Coid J, Yang M, Tyrer $\mathrm{P}_{\text {, et }}$ al. Prevalence and correlates of personality disorder in Great Britain. Br J Psychiatry 2006;188:423-31.

2. Diagnostic and Statistical Manual of Mental Disorders. 5th edn. Washington DC American Psychiatric Association, 2013.

3. Wilkinson-Ryan $\mathbf{T}$, Westen $\mathrm{D}$. Identity disturbance in borderline personality disorder: an empirical investigation. Am J Psychiatry 2000;157:528-41.

4. Berg-Nielsen TS, Vikan A, Dahl AA. Parenting related to child and parental psychopathology: a descriptive review of the literature. Clin Child Psychol Psychiatry 2002; 7:1045-359.

5. Nomura Y, Wickramaratne PJ, Warner V, et al. Family discord, parental depression, and psychopathology in offspring: ten-year follow-up. J Am Acad Child Adolesc Psychiatry 2002; 41:402-9.

6. Ohannessian CM, Hesselbrock VM, Kramer J, et al. The relationship between parental psychopathology and adolescent psychopathology: an examination of gender patterns. J Emot Behav Disord 2005:13:67-76.

7. Vostanis $\mathbf{P}$, Graves A, Meltzer $\mathrm{H}$, et al. Relationship between parental psychopathology, parenting strategies and child mental health--findings from the GB national study. Soc Psychiatry Psychiatr Epidemiol 2006;41:509-14.

8. Gunderson JG. Borderline personality disorder, second edition: a clinical guide. American Psychiatric Pub, 2009.

9. Stepp SD, Whalen DJ, Pilkonis PA, et al. Children of mothers with borderline personality disorder: identifying parenting behaviors as potential targets for intervention. Personal Disord 2012;3:76-91.

10. Von Elm E, Altman DG, Egger $M$, et al. The strengthening the reporting of observational studies in epidemiology [STROBE] statement: guidelines for reporting observational studies. Gac Sanit 2008;22:144-50.

11. Bolignano D, Mattace-Raso F, Torino C, et al. The quality of reporting in clinical research: the CONSORT and STROBE initiatives. Aging Clin Exp Res 2013;25:9-15.

12. Jadad AR, Moore RA, Carroll $D$, et al. Assessing the quality of reports of randomized clinical trials: is blinding necessary? Control Clin Trials 1996;17:1-12.

13. Newman LK, Ste CS, Bergman LR, et al. Borderline personality disorder, mother-infant interaction and parenting perceptions: preliminary findings. Aust $N Z \mathrm{~J}$ Psychiatry 2007;41:598-605

14. Gratz KL, Kiel EJ, Latzman RD, et al. Emotion: empirical contribution. Maternal borderline personality pathology and infant emotion regulation: examining the influence of maternal emotion-related difficulties and infant attachment. J Pers Disord 2014;28:52-69.

15. Crittenden PM, Newman L. Comparing models of borderline personality disorder: mothers' experience, self-protective strategies, and dispositional representations. Clin Child Psychol Psychiatry 2010;15:433-51.

16. Schacht R, Hammond L, Marks M. The relation between mind-mindedness in mothers with borderline personality disorder and mental state understanding in their children. Infant Child Dev 2013;22 (July 2012):68-84.

17. Feldman RB, Zelkowitz $\mathrm{P}$, Weiss $\mathrm{M}$, et al. A comparison of the families of mothers with borderline and nonborderline personality disorders. Compr Psychiatry 1995; 36:157-63

18. White H, Flanagan TJ, Martin A, et al. Mother-infant interactions in women with borderline personality disorder, major depressive disorder, their co-occurrence, and healthy controls. J Reprod Infant Psychol 2011;29:223-35.

19. Barnow S, Spitzer C, Grabe HJ, et al. Individual characteristics, familial experience, and psychopathology in children of mothers with borderline personality disorder J Am Acad Child Adolesc Psychiatry 2006;45:965-72.

20. Crandell LE, Patrick MPH, Hobson RP. 'Still-face' interactions between mothers with borderline personality disorder and their 2-month-old infants. Br J Psychiatry 2003:239-47. 
21. Hobson RP, Patrick M, Crandell $L$, et al. Personal relatedness and attachment in infants of mothers with borderline personality disorder. Dev Psychopathol 2005;17:329-47.

22. Kiel EJ, Gratz KL, Moore SA, et al. The impact of borderline personality pathology on mothers' responses to infant distress. J Fam Psychol 2011:25:907-18.

23. Hobson RP, Patrick MPH, Hobson JA, et al. How mothers with borderline personality disorder relate to their year-old infants. Br J Psychiatry 2009;195:325-30.

24. Abrams KY, Rifkin A, Hesse E. Examining the role of parental frightened/frightening subtypes in predicting disorganized attachment within a brief observational procedure. Dev Psychopathol 2006;18:345-61.

25. Delavenne A, Gratier M, Devouche E, et al. Phrasing and fragmented time in "pathological" mother-infant vocal interaction. Music Sci 2008;12(Suppl 1):47-70.

26. Elliot R, Hunter M, Cooper $\mathrm{G}$, et al. When I look into my baby's eyes... infant emotion recognition by mothers with borderline personality disorder. Infant Ment Health J 2014;35:21-32.

27. Newman L, Stevenson C. Issues in infant-parent psychotherapy for mothers with borderline personality disorder. Clin Child Psychol Psychiatry 2008;13:505-14.

28. Moos BS. Family environment scale manual. Consulting Psychologists Press, 1994

29. Herr NR, Hammen C, Brennan PA. Maternal borderline personality disorder symptoms and adolescent psychosocial functioning. J Pers Disord 2008;22 451-65.

30. Meins E. Security of attachment and the social development of cognition. Psychology Press, 2013.
31. Macfie J, Swan SA. Representations of the caregiver-child relationship and of the self, and emotion regulation in the narratives of young children whose mothers have borderline personality disorder. Dev Psychopathol 2009;21:993-1011.

32. Abela JRZ, Skitch SA, Auerbach RP, et al. The impact of parental borderline personality disorder on vulnerability to depression in children of affectively ill parents. J Pers Disord 2005;19:68-83.

33. Weiss M, Zelkowitz P, Feldman RB, et al. Psychopathology in offspring of mothers with borderline personality disorder: a pilot study. Can J Psychiatry 1996;41:285-90.

34. First MB, Spitzer RL, Gibbon M, et al. The structured clinical interview for DSM-III-R personality disorders (SCID-II). Part I: Description. J Pers Disord 1995;9:83-91.

35. Zanarini MC, Gunderson JG, Frankenburg FR, et al. The revised diagnostic interview for borderlines: discriminating BPD from other axis II disorders. J Pers Disord 1989;3:10-18.

36. Pfohl B, Blum N, Zimmerman M. Structured Interview for DSM-IV Personality: SIDP-IV. American Psychiatric Pub. 1997.

37. Pfohl B, Blum N, John DS, et al. Reliability and validity of the Borderline Evaluation of Severity Over Time (BEST): a self-rated scale to measure severity and change in persons with borderline personality disorder. J Pers Disord 2009;23:281.

38. Murray L, Fiori-Cowley A, Hooper R, et al. The impact of postnatal depression and associated adversity on early mother -infant interactions and later infant outcome. Child Dev 1996:67:2512-26.

39. Macfie J, Swan SA, Fitzpatrick KL, et al. Mothers with borderline personality and their young children: Adult Attachment Interviews, mother -child interactions, and children's narrative representations. Dev Psychopathol 2014;26:539-51. 